\title{
PALEOGEOGRAFIA DA BORDA LESTE DA BACIA DO PARANĀ NO TEMPO DE FORMAÇĀO DAS PRINCIPAIS JAZIDAS DE CARVÃO DO PERMIANO (FORMAÇÕES RIO BONITO E PALERMO)
}

Ricardo da Cunha Lopes (CPRM/PA)

Ernesto Luiz Lavina (NESE/UNISINOS)

Nos anos de 1983 a 1986, a CPRM (SUREGs PA e SP) desenvolveu um projeto de integração de dados de sondagens e de afloramentos, ao longo de toda a borda leste da Bacia do Paraná, obtidos durante programas de pesquisa para carvão. Um dos principais objetivos consistiu na elaboração de uma seção paleoambiental, a partir de poços, nos estados do Rio Grande do Sul, Santa Catarina, Paraná e São Paulo. Dados relativos à parte sul desta seção paleoambiental foram apresentados em trabalhos anteriores (LOPES et alii, 1986; LAVINA \& LOPES, 1987).

A partir da seção paleoambiental e das informações disponíveis na bibliogra fia, construiu-se uma seqthência de mapas paleogeográficos para o intervalo estudado, aqui dados a conhecer (figuras 1 a 3 ).

Ao final da Glaciação Gonduânica houve um extenso episódio transgressivo , onde o mar foi rapidamente inundando todos os continentes, como resposta ao aquecimento climático global.

Na Bacia do Paraná, as primeiras manifestações marinhas foram contemporāneas às ültimas fases da glaciação (formações Mafra e Rio do Sul; SCHNEIDER et alii, 1974). Mapas de isópacas (NORTHFLEET et alii, 1969) e dados faciológicos de roços mostram que o ingresso do mar na bacia fez-se pelo bordo sudoeste, correspondente hoje à região da fronteira entre o Rio Grande do Sul, Argentina e o Uruguai.

Toda a parte final do Permiano Inferior, caracterizou-se por um progressivo crescimento do onlap costeiro, refletindo-se no sistemático aumento da área depo sicional da Bacia. Paralelc a isto, nas fases de estabilização da taxa de cresci mento do onlap costeiro, desenvolveram-se as progradações de mar alto, caracteri zadas por sistemas deltaicos dominados por processos fluviais, nas regiões do sul do Paraná ao norte do Rio Grande do Sul (figura 1). Nas regiões de São Paulo ao norte do Paraná e no Rio Grande do Sul, predominavam litorais dominados por ondas, onde destacavam-se sistemas praiais, estuarinos e barreira-laguna. No Rio Grande do Sul, os estuários desenvolveram-se pelo afogamento progressivo dos vales flúvio-glaciais e os sistemas praiais pelo retrabalhamento por ondas e cor rentes litorâneas dos sedimentos fluviais, deltaicos e estuarinos. Os sistemas 
litorâneos muitas vezes ancoravam-se em pontas do embasamento.

Associados com os sistemas praiais, são encontrados campos de dunas eólicas em diversos locais de São Paulo e Rio Grande do Sul, cujo maior desenvolvimento foi registrado nos municípios de Bagé e Dom Pedrito (RS) (figura 1).

Cabe destacar que neste intervalo de tempo representado, a região do Arco de Ponta Grossa era um elemento ativo, servindo de fonte para os sistemas fluviais (figura 1).

No pulso transgressivo seguinte, em São Paulo e no Paraná, o litoral avançou alén dos limites hoje preservados da Bacia, o mesmo ocorrendo no bordo oeste do Escudo Sul-rio-grandense (figura 2). Em Santa Catarina, os sistemas deltaicos foram afogados e iniciou o desenvolvimento extensivo de cordões litorâneos também nesta região. Nesta fase ocorreu um generalizado desenvolvimento de grandes turfeiras, que irão originar as principais jazidas de carvão no Rio Grande do Sul e sul de Santa Catarina (figura 2). A correlação entre os furos de sonda sugere a existência de pelo menos três grandes pulso transgressivos, aos quais associam-se as distintas fases de geração de turfeiras, como bem caracterizado na região das jazidas do Capané, Iruí e Leão (IAVINA et alii, 1985; LAVINA \& LOPES, 1987).

Com a continuidade do evento transgressivo, o litoral, anteriomente sinuoso, com baías, tende a uma configuração mais retilínea, com direção geral nordeste (figura 3). Esta nova configuração deve-se, em grande parte, ao afogamento parcial da porção oeste do Escudo Sul-rio-grandense e do Arco de Ponta Grossa. Para este tempo, não é mais possivel traçar a linha de praia para os estados de paraná e São Paulo.

Nos pulsos seguintes (parte superior da Formação Palermo), o mar transgride sobre as regiões das turfeiras e a linha de praia posicionou-se em locais onde hoje afloram rochas do Embasamento Pré-Cambriano. Neste tempo, não é mais possível precisar a localização da linha de praia, nem a paleogeografia das áreas emersas.

\section{BIBLIOGRAFIA}

LAVINA, E.L. \& LOPES, R. da C. 1987. A Transgressão Marinha do Permiano Inferior e a Evolução Paleogeográfica do Supergrupo Tubarão no Estado do Rio Grande do Sul. Paula-Coutiana, Porto Alegre, 1:51-103.

LAVINA, E.L.; NOWATZKI, C.H.; SANIOS, M.A.A.; L.EÃO, H.Z. 1985. Ambientes de Sedimentação do Supergrupo Tubarão na Região de Cachøeira do Sul, RS. Acta Geol. Leopoldensia. São Leopoldo, 21:5-68.

LOPES, R. da C.; LAVINA, E.L.; SIGNOREIJI, N. 1986. Fácies Sedimentares e Evolução Paleoambiental do Supergrupo Tubarão na Borda Leste da Bacia do Paraná. Uma Seção Regional nos Estados do Rio Grande do Sul e Santa Catarina. In: Congresso Brasileiro de Geologia, 34, Goiânia, 1986. Anais ... Goiânia, SBG. V. 1, p. 206-218 . 
NORTHFLEET, A.A.; MEDEIROS, R.A.; MUHLMANN, H. 1969. Reavaliação dos Dados Geocronológicos da Bacia do Paraná. Bol. Tec. PETROBRAS, Rio de Janeiro, 12 (3): 291-346.

SCHNEIDER, R.; MUHLMANN, H.; TOMMASI, E.; MEDEIROS, R.A.; DAEMON, R.; NOGUEIRA, A. 1974. Revisão Estratigráfics da Bacia do Paraná. In: Congresso Brasileiro de Geologia, 28, Porto Alegre, 1974. Anais ... Porto Alegre, SBG. v. 1. p. 41-65 . 


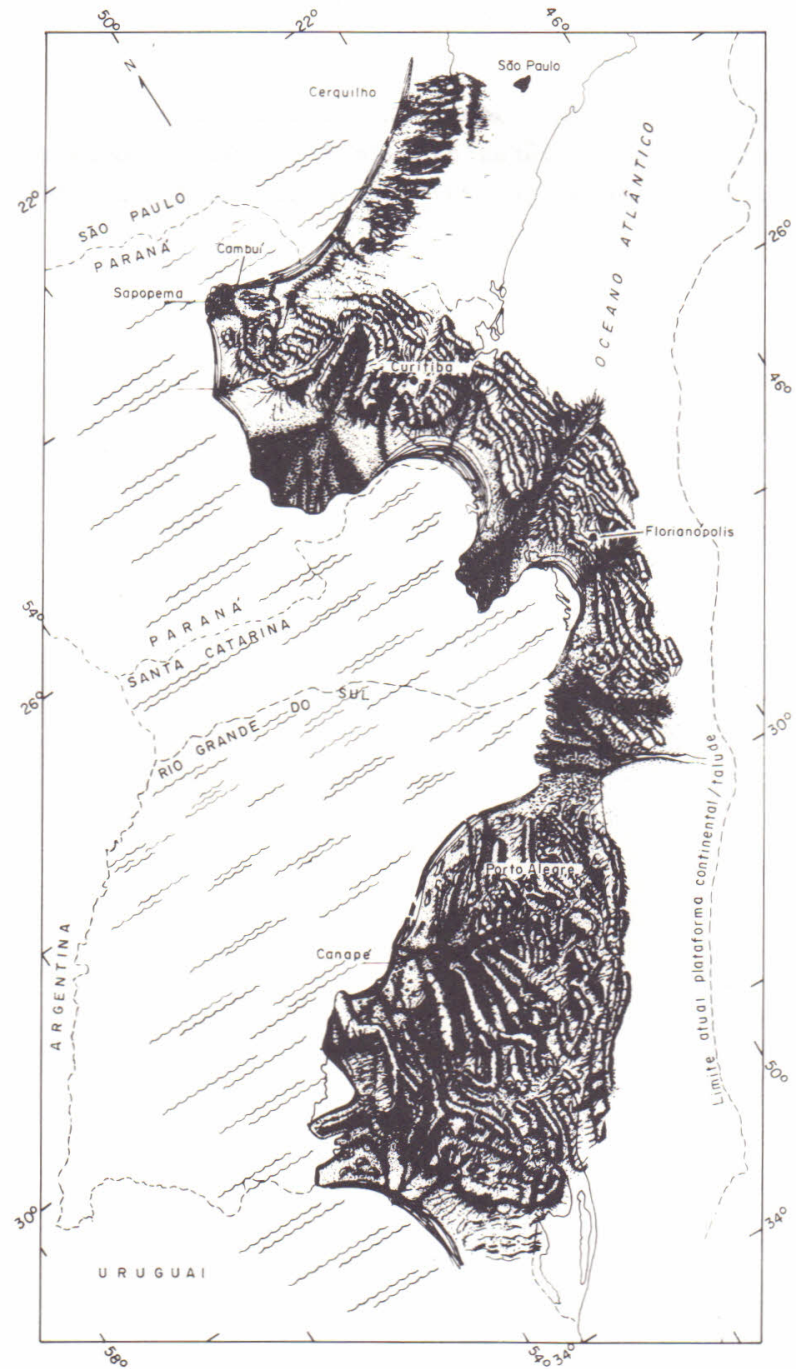

Paleogeografia da Borda Leste da Bocia do Paraná à epoca da formação das turfeiras do Capané, Reserva, Cerquilho, Sopopema e Cambul.

Serras altas
Sedimentos conti-
nentais elitorâneos
Dunos edicas.



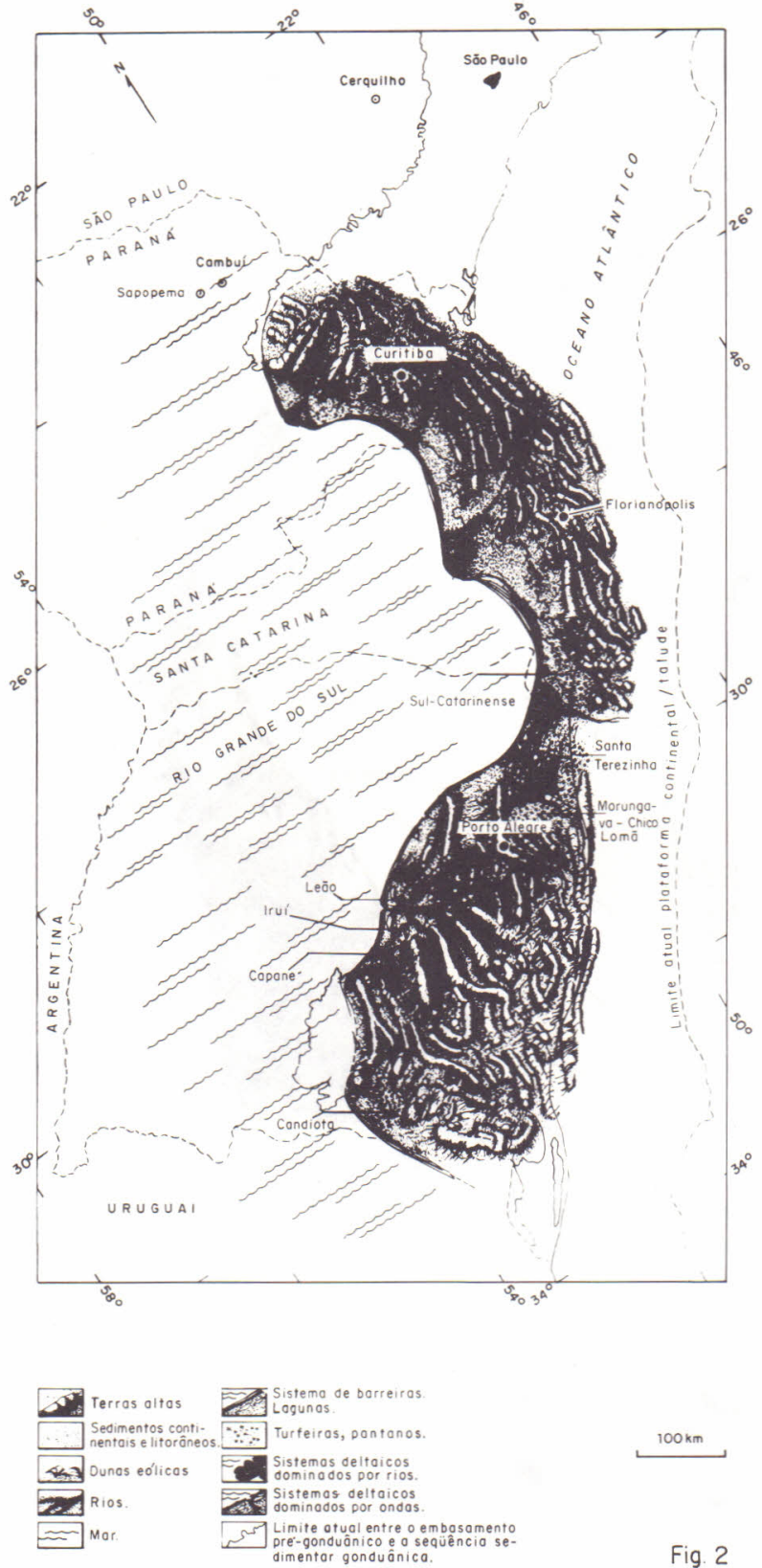

Paleogeografia da Borda Leste do Bocia do Paraná à época da formaçāo das turfeiras de Candiota, Copané(parte superior), Iruí, Leōo(parte inferior), Morungavo - Chico Lomō, Santa Terezinha e Sul-Catarinense. Inicio do afogamento dos sistemas deltaicos dominados por rios, recuo da linha de costa. 

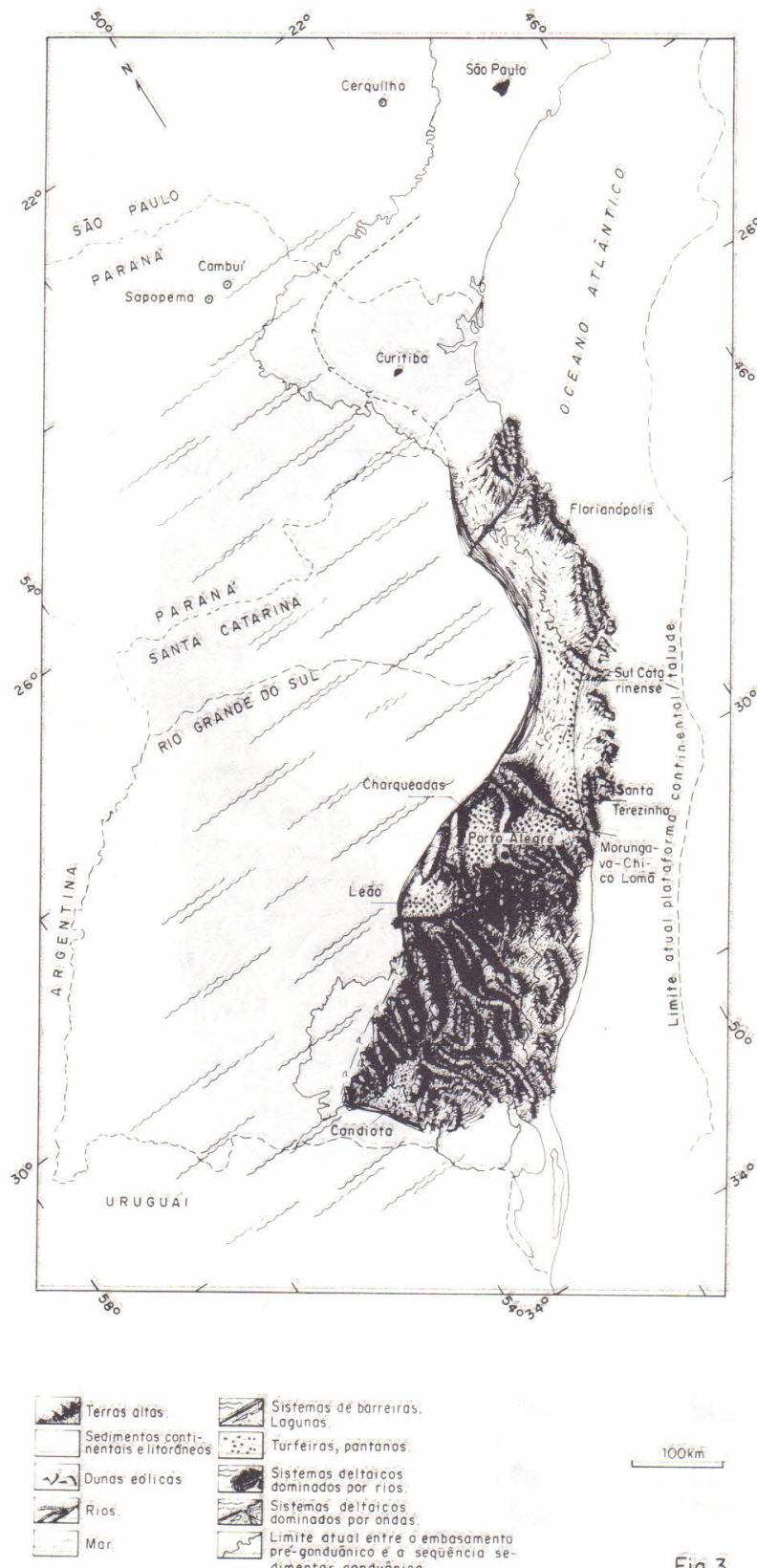
dimentar gonduánica.

Fig. 3

Paleoseografia da Borda Leste do Bacio do Paraná à época da formação dos turfeiros de Candiota (parte superior), Leão, Morungova - Chico Lomá, Santo Terezintio e Sul-Catarinense Útimos estágios do formação de grandes depósitos continentais antes do trans gressoo recobrir todos as áreos baixas. 